\title{
The influence mechanism of household waste separation behavior among college students in the post COVID-19 pandemic period
}

\author{
Chen Zhou ${ }^{1} \cdot$ Xue-juan Fang ${ }^{2,3} \cdot$ Yan-jie Wang ${ }^{1} \cdot$ Qiong Zhang ${ }^{1}$
}

Received: 31 March 2021 / Accepted: 20 January 2022 / Published online: 5 February 2022

(c) Springer Japan KK, part of Springer Nature 2022

\begin{abstract}
College students are one of the most important groups of participants and promoters of household waste separation. Taking Ningbo as a case study, an online + offline questionnaire survey among more than 1700 students in 10 colleges is conducted to identify the main factors and pathways influencing waste separation behavior in the post COVID-19 pandemic period. The results show that the KMO statistic is 0.926 , Bartlet test is $p<0.001$, indicating that questionnaire sample data is suitable for factor analysis. The modified Structural Equation Model test indicates that waste separation behavior of college students mainly results from the combined effect of eight subjective intrinsic factors and seven external situational factors. Among them, the convenience of recycling facilities, the convenience of sorting facilities and the publicity and education of sorting knowledge are the top three factors with the most significant influence. The mean value of epidemic impact factors is 0.277 , which is slightly lower than conventional influence factors (0.289). Environmental Norms and Constraints are an essential component in the analysis framework of college students' waste separation behavior. In the future, society and colleges should give full play to the positive influence of the epidemic factor on college students' waste separation behavior.
\end{abstract}

Keywords Environmental behavior · Household waste separation · College students · COVID-19 pandemic $\cdot$ Structural equation model

\section{Introduction}

Household waste (HW) separation is a reform of the traditional way of waste collection and disposal and is a scientific management method for effective waste disposal. Due to increasing waste production and deteriorating environmental

Xue-juan Fang

xjfang@iue.ac.cn

Chen Zhou

0400117@nbpt.edu.cn

Yan-jie Wang

2020020@nbpt.edu.cn

Qiong Zhang

2014049@nbpt.edu.cn

1 Ningbo Polytechnic, 388 Lushan Road, Ningbo 315800, China

2 Key Lab of Urban Environment and Health, Institute of Urban Environment, Chinese Academy of Sciences, Xiamen 361021, China

3 Institute of Urban Environment, Chinese Academy of Sciences, Xiamen 361021, China conditions, HW separation is one of the most pressing issues of concern in the world to maximize the use of waste resources, reduce waste disposal and improve the quality of the living environment [1-3]. Waste separation and recycling is recognized as effective way to release the conflict of enormous garbage that surrounding the cities and develop urban minerals. Meanwhile, it is of great strategic significance to alleviate resource and environmental constraints, promote the circular economy and accelerate the construction of regional ecological civilization and beautiful China $[4,5]$.

Since the outbreak of the COVID-19 pandemic, the public has been concerned about whether household waste could be a source of contamination and transmission of the virus. Further efforts to separate household waste have received increasing scholarly attention [6-9]. For example, the COVID-19 pandemic attracts more public attention to the household waste classification in their ideology and leads the individuals to strengthen their awareness of environmental behaviors and relevant environmental policies of government [8-10]. In general, waste separation can promote the harmless disposal of household waste and contribution to 
environmental hygiene, which is the guarantee to prevent the spread of various viruses and bacteria. However, compared to the past, the household waste during the COVID-19 pandemic showed new characteristics. On the one hand, due to the epidemic, the public (including college students) stay at home and generated enormous HW in their daily life. For example, more people work at the home office during the COVID-19 pandemic and generated more kitchen waste in three meals a day. On the other hand, personal protective equipment such as masks, disposable gloves, goggles, and other medical wastes have increased significantly due to the epidemic, putting new demands on more elaborate waste separation $[9,10]$.

In China, waste separation is being fully promoted and implemented. On March 18, 2017, the National Development and Reform Commission and the Ministry of Housing and Construction issued the Implementation Plan for the HW Classification System, which requires the implementation of mandatory HW classification in 46 cities in China first, and the recycling rate of HW to reach at $35 \%$ by the end of 2020. Despite the fact that the waste classification policy is being implemented, there are still many people who do not recognize the importance and necessity. Group of college students is the basic element of China's cities. Also, college students have a strong sense of rules and are more active in participating in social activities. If we can motivate college students to participate in HW separation, it will undoubtedly have a strong driving force in waste classification [11]. If college students can bring the waste separation habits developed on campus to their families and society, it will certainly have a greater spreading effect [12].

Post COVID-19 pandemic period refers to a period that the pandemic is under effective control (e.g., China after
April 2020 to the present) but is not eliminated. There will still be a small-scale outbreak in some regions and cities as a result of interregional transmission and seasonal outbreaks $[13,14]$. Therefore, under the dual pressure of waste separation and COVID-19 pandemic, what will be the changes and impacts on the HW separation behavior of college students? Furthermore, how to carry out and promote HW separation activities more efficiently in campus and urban communities? It indicates that it is necessary to explore the influencing factors of HW separation behavior of college students who have been impacted by the epidemic and analyze the degree of different influencing factors.

Ningbo, one of the first 46 pilot cities for waste classification in China, was chosen as the case study area. Ningbo, a coastal port city with a resident population of nearly 10 million, generates 11,000 tons of HW every day, making it an urgent task to break the garbage siege. As the first city in China to use the World Bank loan to classify household waste, Ningbo has basically achieved full coverage of HW separation in the central city since it was launched in 2013, and the public awareness of HW separation has increased from $35.7 \%$ to $93.7 \%$ [15]. Therefore, the selection of the study area has representativeness and typicality. The map of the study area is shown in Fig. 1.

\section{Literature review}

Human environmental behavior is an activity that is influenced by various factors. Therefore, the study of environmental behavior is a complex process. Urban residents' HW separation behavior is one kind of pro-environmental

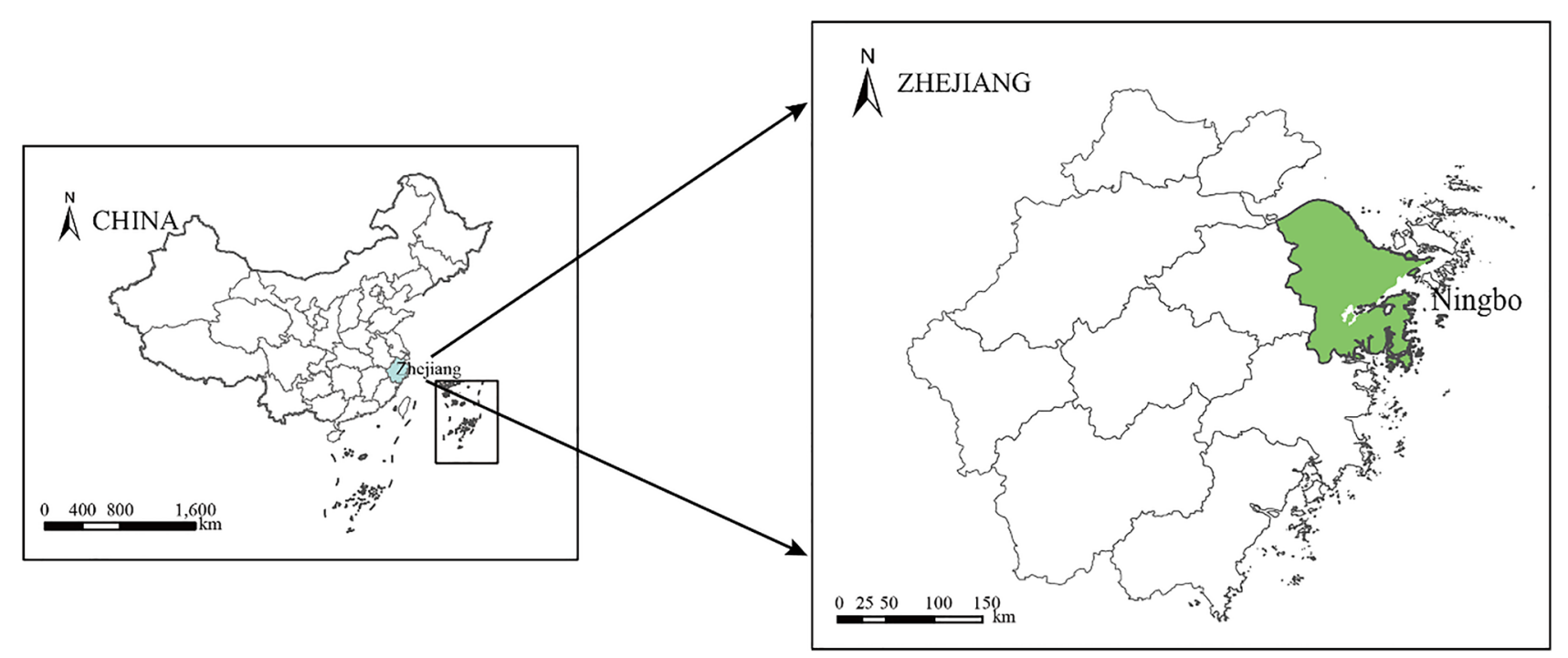

Fig. 1 Map of the study area: Ningbo City in Zhejiang Province, China 
behavior, which has been systematically studied from different theoretical perspectives $[1,4,16]$.

Existing studies on residents' environmental behaviors and choices began with the Theory of Reasoned Action (TRA) in 1975, which proposed that subjective norms and behavioral attitudes jointly influence individual behavioral intentions based on the multi-attribute attitude theory [17]. Later, Ajzen expanded TRA to the Theory of Planned Behavior (TPB) in his book Planned Behavior, which suggested that individual behavior is influenced by three variables: behavioral attitudes, subjective norms, and perceived behavioral control [18]. For example, Chank's study on Hong Kong residents' waste separation behavior showed that information dissemination was one of the main factors influencing individual subjective norms [19]. Nguyen et al. (2015) found that personal moral norms were an important influencing factor in promoting residents' intention to participate in waste separation and recycling behavior [20]. Park and Ha depicted that when residents saw their neighbors or peers separating waste for recycling, their own behavior is also driven and influenced [21]. In addition, scholars have also found that the influence of descriptive norms on perceived behavioral control is a favorable predictor of individual waste separation behavior directly or indirectly [22].

Although the TPB is an inspiration for the study of residential waste disposal behavior, the modeling framework also has strong limitations, as TPB theory mainly considers the subjective factors of individuals. However, the transformation of behavioral intention into real action is also influenced by other external conditions [23, 24]. For example, Stern et al. constructed a model of complex environmental behavior, suggesting that environmental behavior is the result of a combination of relevant external situational factors and subjective factors [25]. Further, Guagnano et al. proposed the ABC (Attitude-Behavior-Condition) theory in 1995, which states that residents' HW recycling behavior is the result of the joint action of residents' attitude variables toward waste recycling and external conditions and argues that the external conditions are a crucial factor in determining whether residents implement recycling behavior [26]. Similarly, Meng et al. found that the influence of external conditions on urban residents' HW separation behavior was nearly two times higher than individual subjective factors in an empirical study in Suzhou, China [24]. In addition, Tucker et al. further refined this model by proposing a research model in which attitudes, subjective and social norms, and external conditions jointly determine residents' HW management behaviors [6]. With the outbreak of the COVID-19 pandemic, many scholars began to discuss the impact of the external condition of the epidemic on residents' environmental behavior, such as the recycling and disposal of medical waste [7, 24]. At the same time, the regular and permanent presence of the epidemic not only changes the waste disposal behavior of the public, but also raises the public's awareness of environmental hygiene [27]. Therefore, there is a strong need to incorporate the impact of the epidemic into the modeling framework of waste separation behavior.

In summary, studies on HW disposal behaviors have focused on urban residents' willingness to do source-separate and its influencing factors. However, few studies have been conducted on the behavioral decision-making mechanisms of college students' participation in source separation and resource recovery, and the constraints and incentives of environmental health events such as the COVID-19 pandemic have been neglected among the external condition factors [8]. Therefore, this paper combined TPB theory, ABC theory, and structural equation modeling methods to construct a conceptual model of college students' HW separation behavior in the post COVID-19 pandemic, taking into account subjective factors and external contextual factors such as the impact of the epidemic, and then designed and conducted an online + offline a questionnaire survey among more than 1700 students from 10 colleges in Ningbo, China. Considering the fact that college students might produce urban $\mathrm{HW}$, these well-educated college students could shoulder the responsibilities in promoting the source separation of HW, because they are strongly aware of and capable of learning new knowledge about environmental protection. Therefore, in the post COVID-19 pandemic period, it is of great theoretical significance and practical value to deeply explore the main factors influencing college students' HW separation behavior and formulate targeted measures to improve their participation in waste separation and recycling, to cultivate urban residents to form HW source separation habits and improve urban environmental management [12, 28].

Compared with the existing studies, the main contributions of this study are as follows: (1) A conceptual model of college students' HW separation behavior decisions in the post COVID-19 pandemic period is constructed, and the impact of the pandemic on environmental awareness and behavior is added to the original TPB and ABC theoretical systems. (2) Comparing to existing attention to urban residents and the community scale, the scope of this study is the behavior of college students in the city because college students are direct and efficient in receiving environmental education. They play an important role in influencing community environmental behavior. (3) This study provides feasible suggestions for the implementation of regular environmental education and policy-making in the post COVID19 pandemic period.

\section{Methodology}

\section{Model design}

In recent years, many scholars have conducted extensive research on the influencing factors of residents' HW disposal 
behavior. According to the literature [22, 24], this paper summarizes four factors that frequently appeared and have a significant impact on residents' HW separation behavior, i.e., Environmental Attitude and Consciousness (EAC), Environmental Knowledge and Education (EKE), Environmental Norms and Constraints (ENC), Environmental Facilities and Services (EFS). In the perspective of model design, not only influencing factors of general residents' waste disposal behavior are considered, but also related influencing factors of college students' unique behavior under the epidemic situation are taken into consideration because college students have formed a different community.

1. EAC Previous studies have discussed that there is a significant correlation between residents' environmental consciousness and waste separation behavior [29-31]. At present, the concept of EAC has not been clearly defined. This paper defines EAC as college students' general and stable feelings or positions on the behavior of HW separation and recycling. In the survey, four indicators have been employed to reflect college students' EAC, i.e., awareness of resource conservation and environmental protection $\left(\mathrm{EAC}_{1}\right)$, willingness to participate $\left(\mathrm{EAC}_{2}\right)$, environmental hygiene awareness $\left(\mathrm{EAC}_{3}\right)$, and change of environmental behavior attitude in the epidemic situation $\left(\mathrm{EAC}_{4}\right)$. Among them, $\mathrm{EAC}_{3}$ and $\mathrm{EAC}_{4}$ are epidemic-related indicators added in this study to investigate the change of college students' attitudes and consciousness of environmental health after the outbreak of COVID-19. It is meaningful to analyze whether the outbreak of the epidemic has enhanced the consciousness of environmental protection from college students and transformed into the enthusiasm of waste separation behavior.

2. EKE Previous results have shown that there is a strong positive correlation between environmental publicity and residents' participation in waste collection [32, 33]. Meanwhile, some scholars point out that there is a significant correlation between residents' environmental knowledge and their environmental behavior, and the lack of relevant knowledge will constrain residents from participating in waste separation and recycling. The definition of EKE is that college students are exposed to the knowledge, skills and information related to waste separation and recycling such as waste classification method, recycling requirements, recycling ways, recycling network location, recycling hotline and other information through classroom education, lectures, community activities, media advertising, etc. [24]. Through extensive environmental publicity and education, college students can better understand the new recycling policies and waste separation requirements (including the recycling requirements during the epidemic period) and improve the separation and recycling ability and implementation [34, 35]. In this study, four indicators are used to denote the environmental knowledge and education of college students, i.e., basic knowledge of classified recycling $\left(\mathrm{EKE}_{1}\right)$, classification publicity and education $\left(\mathrm{EKE}_{2}\right)$, publicity and education intensity after the epidemic $\left(\mathrm{EKE}_{3}\right)$, and knowledge learning approach $\left(\mathrm{EKE}_{4}\right)$. Among them, $\mathrm{EKE}_{3}$ is an epidemicrelated indicator to investigate whether college students have received more frequent publicity and been educated on waste classification after the outbreak of the epidemic, which can have an impact on waste separation behavior. Also, considering the particularity of colleges and universities, the forms of waste separation publicity activities are more diversified in the group of college students than community residents. (Publicity activities are more diversified in college such as lectures, student performances, knowledge competitions, etc.) Therefore, the knowledge publicity and learning approaches $\left(\mathrm{EKE}_{4}\right)$ is added.

3. ENC Social norm refers to the pressure from others and society that has a significant impact on individual behavior, in the form of approval or disapproval of others, and the sense of pride or shame associated with it [36]. Social norms play an important role in coordinating human environmental behavior. Society, schools, and other relevant departments can promote the implementation of environment-friendly behavior by activating the environmental and social norms of residents or college students, so as to realize the positive effect on environmental governance and environmental behavior [37]. Previous studies have also shown that there is a significant correlation between ENC and residents' waste separation behavior [38]. The existing studies on ENC mainly focus on four aspects, i.e., sense of social responsibility [20], the binding effect of laws and regulations $[39,40]$, herd behavior effect [21] and social recognition [24]. This paper defines ENC as the pressure from others and society that has an important impact on college students and the degree to which college students tend to develop a certain waste separation behavior. Also, the social responsibility of college students $\left(\mathrm{ENC}_{1}\right)$, the influence of surrounding classmates $\left(\mathrm{ENC}_{2}\right)$, the leading role of activists $\left(\mathrm{ENC}_{3}\right)$, and the binding role of school discipline and rules $\left(\mathrm{ENC}_{4}\right)$ are used to evaluate the ENC of college students. Among them, ENC1 is an epidemic-related indicator to investigate whether college students regard waste separation behavior as a social norm to fulfill their social responsibilities and mission of the times. Considering the top-down strategy adopted by colleges and universities in the implementation of environmental education and other policies, and taking the exemplary leadership of student cadres (include but 
not limit to Party members, applicants for membership of the Party, member of the student union, etc.) as an important embodiment, indicator $\mathrm{ENC}_{3}$ is used.

4. EFS it is found that external factors have an important impact on residents' HW separation behavior [41, 42]. For example, the existence of the informal recycling market, to a certain extent, improves the convenience of residents' waste disposal and promotes the implementation of residents' waste separation behavior [43]. Also, an increasing number of recycling sites (including intelligent recycling points) will help to improve the recycling rate of renewable resources $[44,45]$. In addition, whether it takes too much time for students to sort out waste, whether there are waste sorting facilities and tools in the dormitory, and whether there is enough space for waste storage will also affect whether college students participate in sorting and recycling [46]. In this survey, the following five indicators have been used to reflect the environmental facilities and services: the incentive of economic benefits of waste separation $\left(\mathrm{EFS}_{1}\right)$, the cost of time in HW separation $\left(\mathrm{EFS}_{2}\right.$ ), the convenience of sorting facilities $\left(\mathrm{EFS}_{3}\right)$, the convenience of recycling facilities $\left(\mathrm{EFS}_{4}\right)$, and the good operation of recycling facilities $\left(\mathrm{EFS}_{5}\right)$. Among them, $\mathrm{EFS}_{5}$ is an epidemicrelated indicator to investigate whether the operation of waste separation facilities has been guaranteed and operated after the outbreak of COVID-19.

The results of the variables' setup are shown in Table 1.

\section{Theoretical model and research hypothesis}

Based on the previous literature review and summary of the possible influencing factors of residents' waste disposal behavior, combined with the Theory of Planned Behavior and the living conditions of college students, the initial model of college students' decision-making concerning household waste separation and recycling is constructed (Fig. 2). The hypotheses are that EAC, EKE, ENC, and EFS will have an impact on college students' HW separation behavior, and 17 observed variables are set in Table 1 . Among them, $\mathrm{EAC}_{3}, \mathrm{EAC}_{4}, \mathrm{EKE}_{3}, \mathrm{ENC}_{1}, \mathrm{ENC}_{3}$ and $\mathrm{EFS}_{5}$ are epidemic-related variables.

Based on the above conceptual model, the following basic path assumptions are proposed;

1. $\mathrm{H}_{1}-\mathrm{H}_{4}$ : It is assumed that $\mathrm{EAC}_{1}, \mathrm{EAC}_{2}, \mathrm{EAC}_{3}$ and $\mathrm{EAC}_{4}$ have a positive effect on college students' EAC respectively, and the corresponding hypothesis $\mathrm{H}_{1}, \mathrm{H}_{2}, \mathrm{H}_{3}$ and $\mathrm{H}_{4}$ are established.
2. $\mathrm{H}_{5}-\mathrm{H}_{8}$ : It is assumed that $\mathrm{EKE}_{1}, \mathrm{EKE}_{2}, \mathrm{EKE}_{3}$ and $\mathrm{EKE}_{4}$ have a positive effect on college students' EKE, respectively, and the corresponding hypothesis $\mathrm{H}_{5}, \mathrm{H}_{6}, \mathrm{H}_{7}$ and $\mathrm{H}_{8}$ are established.

3. $\mathrm{H}_{9}-\mathrm{H}_{12}$ : It is assumed that $\mathrm{ENC}_{1}, \mathrm{ENC}_{2}, \mathrm{ENC}_{3}$ and $\mathrm{ENC}_{4}$ have a positive impact on the ENC of college students, and the corresponding hypothesis $\mathrm{H}_{9}, \mathrm{H}_{10}, \mathrm{H}_{11}$ and $\mathrm{H}_{12}$ are established.

4. $\mathrm{H}_{13}-\mathrm{H}_{17}$ : It is assumed that $\mathrm{EFS}_{1}, \mathrm{EFS}_{3}, \mathrm{EFS}_{4}$ and $\mathrm{EFS}_{5}$ have a positive impact on the EFS of college students, and the corresponding hypothesis are $\mathrm{H}_{13}, \mathrm{H}_{15}, \mathrm{H}_{16}$ and $\mathrm{H}_{17}$. It is assumed that $\mathrm{EFS}_{2}$ have a negative impact on college students' EFS, and the corresponding hypothesis $\mathrm{H}_{14}$ is established.

In addition, considering the possible mutual influence between the four latent variables, combined with relevant existing literatures [20, 22], three relationship paths between the latent variables are added. Specifically, the relationship between EAC and ENC, which reflects the relevant impact of environmental behavior attitude and individual behavior norms; the relationship between EAC and EKE, which reflects the related influence of environmental behavior attitude and environmental knowledge; the relationship between ENC and EFS, which reflects the relevant impact of environmental norms of conduct and environmental service facilities.

\section{Questionnaire survey}

According to the theoretical model, the Likert scale 5-level method is selected to design the questionnaire of college students' HW separation behavior, i.e., all the measurement of the questionnaire ranging from "strongly agree", "agree", "moderate", "disagree" to "strongly disagree" according to the scale of $1-5$ points [24].

The first step is to conduct a pilot test through extensive class discussion, collect 150 initial questionnaires, modify and redesign the number, order and content of the questionnaires according to the survey results and then get the final version of the formal questionnaire.

In the second step, 10 colleges (5 undergraduate universities and 5 higher vocational colleges) in Ningbo were selected as the sampling areas to carry out offline field survey and online survey via the software Questionnaire Star from April to June in 2020. Questionnaire Star is an online survey platform in mainland China, which provides functions equivalent to Amazon Mechanical Turk [47]. Affected by the epidemic control policy, some colleges are not accessible to participate in field research and discussion, so the online survey is adopted. Samples collected from filed research accounts for 45\%, while samples from Questionnaire Star accounts for 55\%. Since 2017, colleges in Ningbo 
Table 1 Setting and basis of latent variables and observed variables of hypothesis model

\begin{tabular}{|c|c|c|c|}
\hline Latent variables & $\begin{array}{l}\text { Observed } \\
\text { variables }\end{array}$ & Variable description & References \\
\hline \multirow[t]{4}{*}{$\begin{array}{l}\text { Environmental Attitude and Consciousness } \\
\text { (EAC) }\end{array}$} & $\mathrm{EAC}_{1}$ & $\begin{array}{l}\text { There are more and more household wastes in cities and colleges. It is } \\
\text { very important and necessary to classify wastes }\end{array}$ & {$[24,34]$} \\
\hline & $\mathrm{EAC}_{2}$ & $\begin{array}{l}\text { I am willing to participate in HW classification and recycling, which can } \\
\text { save resources and protect the environment }\end{array}$ & {$[20,29,30]$} \\
\hline & $\mathrm{EAC}_{3}$ & $\begin{array}{l}\text { The outbreak of the Covid-19 has deepened my understanding of environ- } \\
\text { mental health and safety }\end{array}$ & New add \\
\hline & $\mathrm{EAC}_{4}$ & $\begin{array}{l}\text { The outbreak of the Covid-19 increased my enthusiasm to participate in } \\
\text { household waste classification }\end{array}$ & New add \\
\hline \multirow{4}{*}{$\begin{array}{l}\text { Environmental Knowledge and Education } \\
\text { (EKE) }\end{array}$} & $\mathrm{EKE}_{1}$ & I know the basic knowledge and requirements of HW separation & {$[33,46]$} \\
\hline & $\mathrm{EKE}_{2}$ & I have received enough HW sorting publicity and education & {$[24,32]$} \\
\hline & $\mathrm{EKE}_{3}$ & $\begin{array}{l}\text { After the Covid-19 outbreak, I received more frequent publicity and } \\
\text { education on HW classification at school }\end{array}$ & New add \\
\hline & $\mathrm{EKE}_{4}$ & $\begin{array}{l}\text { Diversified and diverse forms of publicity and education have promoted } \\
\text { my participation in HW classification }\end{array}$ & New add \\
\hline \multirow[t]{4}{*}{$\begin{array}{l}\text { Environmental Norms and Constraints } \\
\text { (ENC) }\end{array}$} & $\mathrm{ENC}_{1}$ & $\begin{array}{l}\text { In the post-epidemic period, it is my social responsibility and mission to } \\
\text { participate in HW separation }\end{array}$ & $\begin{array}{l}{[36,38]} \\
\text { Improved }\end{array}$ \\
\hline & $\mathrm{ENC}_{2}$ & $\begin{array}{l}\text { My classmates and friends take part in waste sorting, which also drives } \\
\text { my enthusiasm }\end{array}$ & {$[21,37]$} \\
\hline & $\mathrm{ENC}_{3}$ & $\begin{array}{l}\text { Participating in HW separation in the post COVID-19 pandemic period is } \\
\text { an exemplary embodiment of activists }\end{array}$ & New add \\
\hline & $\mathrm{ENC}_{4}$ & $\begin{array}{l}\text { The laws and regulations of HW classification can play a constraint and } \\
\text { promotion role for me }\end{array}$ & {$[34,39]$} \\
\hline \multirow{5}{*}{$\begin{array}{l}\text { Environmental Facilities and Services } \\
\text { (EFS) }\end{array}$} & $\mathrm{EFS}_{1}$ & Waste sorting and recycling facilities have economic returns & {$[44,45]$} \\
\hline & $\mathrm{EFS}_{2}$ & HW separation and recycling waste of my time & {$[24,43,46]$} \\
\hline & $\mathrm{EFS}_{3}$ & $\begin{array}{l}\text { There are classified garbage bins and garbage kiosks in the campus, with } \\
\text { clear identification and close distances }\end{array}$ & {$[26,44]$} \\
\hline & $\mathrm{EFS}_{4}$ & $\begin{array}{l}\text { The campus is conveniently equipped with intelligent garbage collection } \\
\text { facilities }\end{array}$ & {$[24,41,45]$} \\
\hline & $\mathrm{EFS}_{5}$ & $\begin{array}{l}\text { After the Covid-19 outbreak, garbage collection facilities operated better } \\
\text { and maintained without breakdowns }\end{array}$ & New add \\
\hline
\end{tabular}

New added variables refer to the first appeared variables in this study, which do not appear in the existing and traditional influencing factors of garbage classification. Improved variables refer to the variable which has appeared in the existing literature but has been redesigned the presentation form in the study. For example, variables such as $\mathrm{EAC}_{3}, \mathrm{EAC}_{4}, \mathrm{EKE}_{3}, \mathrm{ENC}_{1}, \mathrm{ENC}_{3}$ and $\mathrm{EFS}_{5}$ take a range of the epidemic effects into account

have started to implement HW separation, and launched the "Colleges Aiding Other Schools" campus waste separation pattern, in order to initiate the HW separation among the public [18].

The third step is questionnaire collection. A total number of 1799 questionnaires were collected, including 1720 valid ones, with an effective recovery rate of $95.61 \%$. The distribution of socio-demographic characteristics of the collected samples is shown in Table 2.

\section{Structural equation model}

The Structural Equation Model (SEM) is an important statistical method in quantitative research. It integrates analysis of variance, regression analysis, path analysis and factor analysis, and is used to estimate and verify causal model, a multiple variable complex relationship modeling tools [48, 49]. SEM simulates the relationship between multiple independent and dependent variables, which helps to answer a set of related research questions in a single analytical framework [50]. At present, SEM has been widely used in sociology, psychology, economics, geography, politics, marketing and other fields [51]. In the field of environment, SEM has been widely used in environmental education, environmental behavior analysis [24] and the impact mechanism of environmental pollution [52].

There are two basic models in SEM as follows: measured model and structural model. The measured model consists of latent variables and observed variables (also known as manifest variables or measured indicators). Mathematically defined, a measured model is a linear function of a set of observed variables. For example, a 


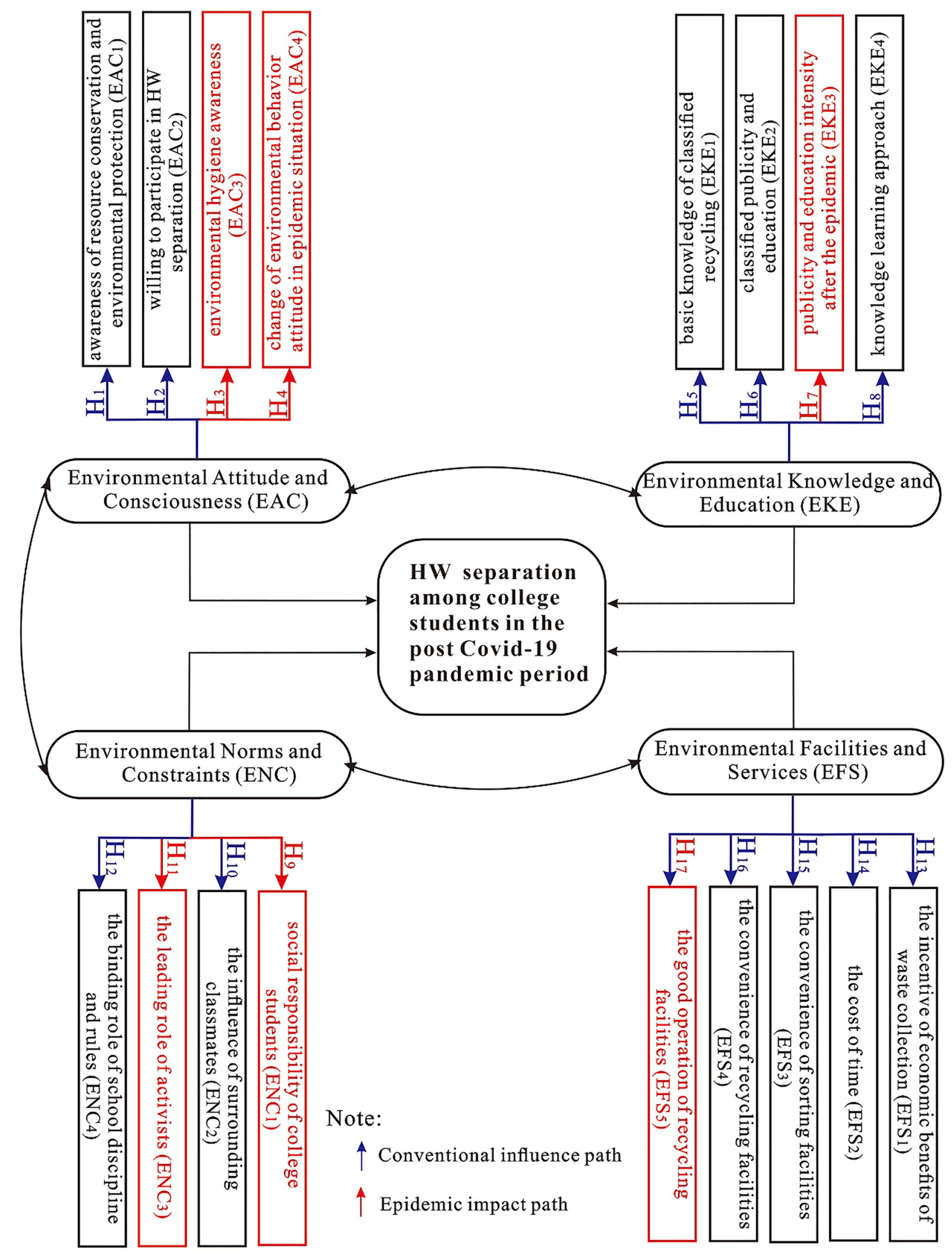

Fig. 2 Theoretical model of the influence mechanism of college students' HW separation behavior in the post COVID-19 pandemic period 
Table 2 Socio-demographic characteristics of the survey samples

\begin{tabular}{|c|c|c|c|c|}
\hline \multirow[t]{2}{*}{ Social attribute characteristics } & \multirow[t]{2}{*}{ Classification/grading } & \multicolumn{2}{|l|}{ Samples } & \multirow[t]{2}{*}{ Explanation } \\
\hline & & Frequency & Proportion $(\%)$ & \\
\hline \multirow[t]{2}{*}{ Gender } & Male & 715 & 41.57 & \multirow[t]{2}{*}{-} \\
\hline & Female & 1005 & 58.43 & \\
\hline \multirow[t]{2}{*}{ Education level } & Bachelor degree & 1619 & 94.13 & \multirow[t]{2}{*}{-} \\
\hline & Postgraduate or above & 101 & 5.87 & \\
\hline \multirow[t]{2}{*}{ Students' political attributes } & Attribute of CPC Member & 419 & 24.36 & \multirow[t]{2}{*}{ Party membership activists, CPC members, etc } \\
\hline & Non-party member attribute & 1301 & 75.64 & \\
\hline \multirow[t]{2}{*}{ Professional background } & Related & 332 & 19.31 & \multirow{2}{*}{$\begin{array}{l}\text { Whether the professional courses are related to HW } \\
\text { sorting knowledge }\end{array}$} \\
\hline & Unrelated & 1388 & 80.69 & \\
\hline \multirow[t]{2}{*}{ Social background } & Classification & 1308 & 76.05 & \multirow{2}{*}{$\begin{array}{l}\text { HW separation in the community where the student's } \\
\text { family is located }\end{array}$} \\
\hline & No classification & 412 & 23.95 & \\
\hline \multirow[t]{5}{*}{ Family monthly income } & Below 3000 (Yuan) & 230 & 13.37 & \multirow[t]{5}{*}{ Monthly average income of the family } \\
\hline & $3000-5000$ (Yuan) & 423 & 24.59 & \\
\hline & $5001-10,000$ (Yuan) & 614 & 35.70 & \\
\hline & $10,001-20,000$ (Yuan) & 305 & 17.73 & \\
\hline & Above 20,000 (Yuan) & 148 & 8.60 & \\
\hline Total samples & \multicolumn{4}{|c|}{1720 valid questionnaires ( 1799 were recovered in total, with an effective recovery rate of $95.61 \%$ ) } \\
\hline
\end{tabular}

measured model of SEM with three observed variables is shown in Supplementary Fig. 1. The regression equation of the above measured model is as follows:

$\left\{\begin{array}{l}X_{1}=\beta_{1} \xi_{1}+\delta_{1} \\ X_{2}=\beta_{2} \xi_{1}+\delta_{2} \\ X_{3}=\beta_{3} \xi_{1}+\delta_{3}\end{array} \quad\left\{\begin{array}{l}Y_{1}=\beta_{4} \xi_{2}+\varepsilon_{1} \\ Y_{2}=\beta_{5} \xi_{2}+\varepsilon_{2} \\ Y_{3}=\beta_{6} \xi_{2}+\varepsilon_{3}\end{array}\right.\right.$.

The above regression equation can be expressed by matrix equation as follows:

$\left\{\begin{array}{l}X=\Delta_{X} \xi_{1}+\delta \\ Y=\Delta_{Y} \xi_{2}+\varepsilon\end{array}\right.$,

where, $\xi_{1}$ and $\xi_{2}$ are latent variables. In this study, four latent variables are established, namely EAC, EKE, ENC and EFS, respectively. $\mathrm{X}\left(X_{1}, X_{2}, X_{3}\right)$ and $\mathrm{Y}\left(Y_{1}, Y_{2}, Y_{3}\right)$ are observed variables. In this study, a total of 17 observed variables $\left(\mathrm{EAC}_{1}-\mathrm{EAC}_{4}, \mathrm{EKE}_{1}-\mathrm{EKE}_{4}, \mathrm{ENC}_{1}-\mathrm{ENC}_{4}\right.$, $E S_{1}-E S_{5}$ ) are initially designed, as shown in Table 1. $\Delta_{X}$ and $\Delta_{Y}$ are the factor loading of the observed variable $(\mathrm{X}, \mathrm{Y}) . \delta\left(\delta_{1}, \delta_{2}, \delta_{3}\right)$ and $\varepsilon\left(\varepsilon_{1}, \varepsilon_{2}, \varepsilon_{3}\right)$ are the measurement errors (residual errors) of observed variables, respectively. $\beta_{1}-\beta_{6}$ refers to the influence coefficient estimated by the model.

The structural model explains the causal relationship model between latent variables. In this study, we explore the degree to which HW separation behavior of college students is affected by four latent variables in the post COVID19 pandemic period. The specific structural equation is as follows:
$\mathrm{HWsp}=\alpha_{1} \xi_{1}+\alpha_{2} \xi_{2}+\cdots \alpha_{n} \xi_{n}+\zeta$

Among them, HWsp is the endogenous latent variable representing the target result. This study focuses on the intentions of college students participating in HW separation behavior. $\alpha_{1}-\alpha_{n}$ refers to the influence coefficient estimated by exogenous latent variable $\xi_{1} \sim \xi_{n}$, in this study, $n=4$. Combined with Formula (1), it can be considered that the value of $\alpha_{1} * \beta_{1}$ is the influencing degree of observed variable $X_{1}$ on "HW separation behavior of college students". The specific results are shown in the sensitivity coefficients in Table 4 . $\zeta$ is a random term of the model system. Software AMOS22.0 is used to evaluate the total effect of each predictive variable on the latent variable, and Maximum Likelihood Estimation (MLE) is adopted to estimate the model parameters [24]. In order to verify the suitability of the measured model and the endogeneity of multiple variables, the Modification Indices (MI) are selected to carry out the initial test, and then the initial SEM is modified.

The technical route of this study and the basic procedure of SEM is shown in Fig. 3.

\section{Results}

\section{Survey data inspection}

To test the rationality of the model parameter setting, software SPSS25.0 is used to analyze the reliability and validity of the questionnaire data. The reliability of the data is tested by calculating the Cronbach's Alpha of the data of all 
Fig. 3 Technical route and basic steps of structural equation model

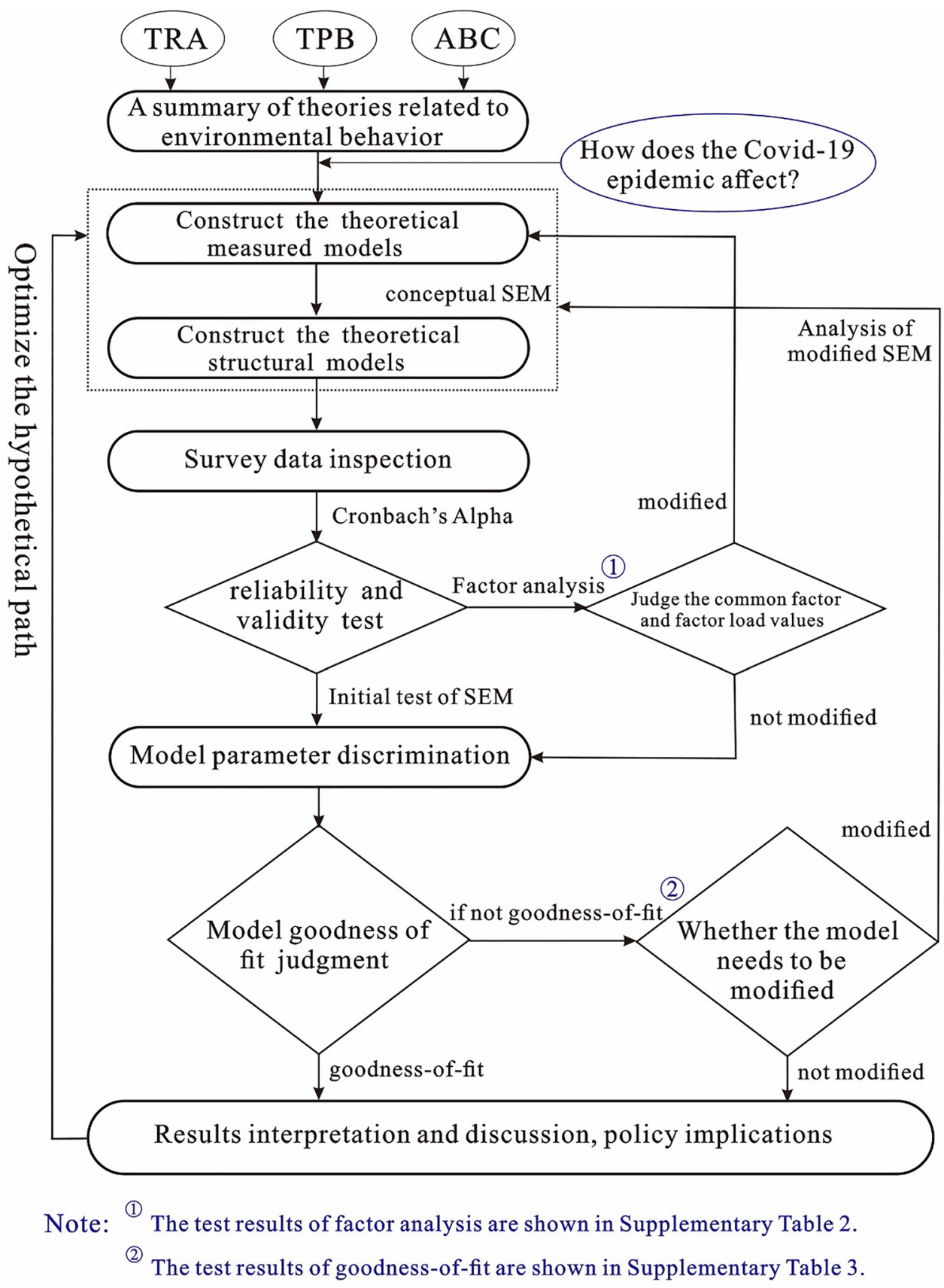

observation variables [53]. According to the research conclusion of Liu et al., if the reliability coefficient is greater than 0.7 , the overall reliability of the data is good [54]. The reliability test results of this study are shown in Supplementary Table 1. The Cronbach's Alpha coefficients of all variables are above 0.7 . Besides, the Cronbach's alpha value of the total measurement is 0.901 , indicating that the overall reliability of the data is good and the data are reliable.

Furthermore, Kaiser-Meyer-Olkin (KMO) test and Bartlet sphere test are first performed before factor analysis. When the KMO test coefficient is above 0.6 and the significance level of the Bartlet test is lower than 0.05, the questionnaire has structural validity and can be used for factor analysis. The results show that the KMO statistic is 0.926 , the significance level of the Bartlet test is $p<0.001$, which indicates that the validity of data is good, and the questionnaire data are suitable for factor analysis. Then, SPSS25.0 is used to do exploratory factor analysis on the sample data of 17 observation variables. The Oblimin Rotation is used to analyze four common factors. It is a general form for obtaining oblique rotations used to transform vectors associated with principal component analysis or factor 
analysis to simple structure [55]. The factor load matrix after orthogonal rotation is shown in Supplementary Table 2.

According to the factor load matrix, whether the latent variable setting, observation variable separation,,, and set in the conceptual model (Fig. 2) are reasonable or not could be examined. In the initial conceptual model, the factor loading values of $\mathrm{EFS}_{2}$ are less than 0.5 regardless of the common factor, so this observed variable is removed from the initial measured model. A possible reason for this is that college students often have meals in the canteen and live in the dormitories which are basically equipped with waste sorting tools, and thus time spent on waste separation is not much. Moreover, college dormitory regulation requires the dormitory members to take duty, so $\mathrm{EFS}_{2}$ has a negligible effect on waste separation behavior, and $\mathrm{H}_{14}$ is assumed as the deletion path.

It can be seen from Supplementary Table 2 in general, common Factor 1, also known as EKE, contains four observed variables $\mathrm{EKE}_{1}-\mathrm{EKE}_{4}$. Likewise, common Factor 2, known as EFS, contains three observed variables $\mathrm{EFS}_{3}-\mathrm{EFS}_{5}$; and common Factor 3, known as ENC, contains three observed variables $\mathrm{ENC}_{1}, \mathrm{ENC}_{3}$, and $\mathrm{ENC}_{4}$; common Factor 4, known as EAC, contains three observed variables $\mathrm{EAC}_{1}-\mathrm{EAC}_{3}$.

Specially, $\mathrm{EAC}_{4}$ is an observed variable under latent variable EAC in initial SEM. However, the most factor loading value of $\mathrm{EAC}_{4}$ under the common Factor 1 is 0.737 . It shows the awareness of environmental protection and waste separation of college students is increasing due to the epidemic impact because the measurements during the epidemic also work as a kind of environmental education. For example, as a result of the epidemic, college students knew that when pills have expired, their chemical substances would be invalid or denatured, so expired drugs and packaging belong to hazardous waste. Similarly, due to the epidemic, college students learned that unused and expired disposable masks belong to dry waste. Therefore, $\mathrm{EAC}_{4}$ should be recategorized as an observed variable of latent variable EKE. Similarly, due to the influence of peers around, $\mathrm{ENC}_{2}$ used to be an observed variable of the latent variable $\mathrm{ENC}$, but its factor loading value under the common factor EKE is the highest, reaching 0.594 , indicating that the waste separation behavior of peers plays the role of educational transmission. Therefore, $\mathrm{ENC}_{2}$ is recategorized as an observed variable of the latent variable EKE. In addition, the economic benefit incentive $\mathrm{EFS}_{1}$ is used to be an observed variable of the latent variable EFS, but its factor loading value under the common factor ENC is the highest reaching 0.605, which indicates that the economic benefit incentive of waste classification facilities is also an incentive to individual environmental norms and behaviors. Therefore, $\mathrm{EFS}_{1}$ is recategorized as an observed variable of the latent variable ENC. Also, the factor load values of the other observed variables are greater than 0.5 , which indicates that these variables can be well explained by the corresponding common factors, and their settings are consistent with the conceptual model. Compared with the research hypotheses and results of Meng et al. [24], it is clear to find that ENC is an indispensable and important component in the analysis framework of college students' waste separation behavior. On the one hand, it comes from the external constraints of society and colleges on waste classification regulations and systems. On the other hand, it comes from the internal constraints of active applicants for membership of the Party and the pursuit of certain economic benefits. This is also related to the compulsory management regulations of waste classification issued by the Ningbo Municipal Government. Regulations of Ningbo Municipality on the separation and management of household waste is fully implemented from October 1, 2019. Individuals are required by the Department of General Sanitation to separate $\mathrm{HW}$; if the one refuses to separate $\mathrm{HW}$, there is a fine range from 20 to 500 yuan.

\section{Initial test of SEM}

Subsequently, Confirmatory Factor Analysis (CFA) was conducted to explore if the survey data set supported the construct extracted from exploratory factor analysis. The test results of the model's fitness are shown in Supplementary Table 3. Chi-square is $631.832(P<0.00)$ and the degree of freedom is 119 . However, the Chi-square degree of freedom ratio $(\mathrm{Cmin} / \mathrm{df})$ is 5.309 , which is more than the better fit range of 3, and the RMSEA range is 0.124 , which is too large for the fitting results of the model. RMSEA range less than 0.08 is acceptable, less than 0.05 , and $P$ value larger than 0.05 is ideal $[24,51]$. Thereafter, composite reliability, loadings with $P$ value, and average variance extracted are calculated (as shown in Supplementary Table 4).

According to the above analysis and adjustment results, the initial SEM for the study of college students' HW separation behavior is constructed on AMOS 22.0, and the ML estimation method is adopted to estimate the parameters in the initial SEM [24]. The initial operation results are shown in Fig. 4. The significance of standardized path coefficient estimation is shown in Table 3.

It can be found that the standardized path coefficient of the impact of "knowledge learning pathway $\mathrm{EKE}_{4}$ " on EKE is only 0.179 , which does not pass the significance test. Theoretically speaking, compared with the community, colleges and universities have more diversified ways of publicity and education. However, for college students, the content of HW classification education is far greater than "forms of education and ways of publicity", which means that more attention should be paid to HW classification knowledge and resource recycling knowledge in the follow-up environmental education process, and not stick to the diversification of publicity 
Fig. 4 Results of parameter estimation of the initial SEM

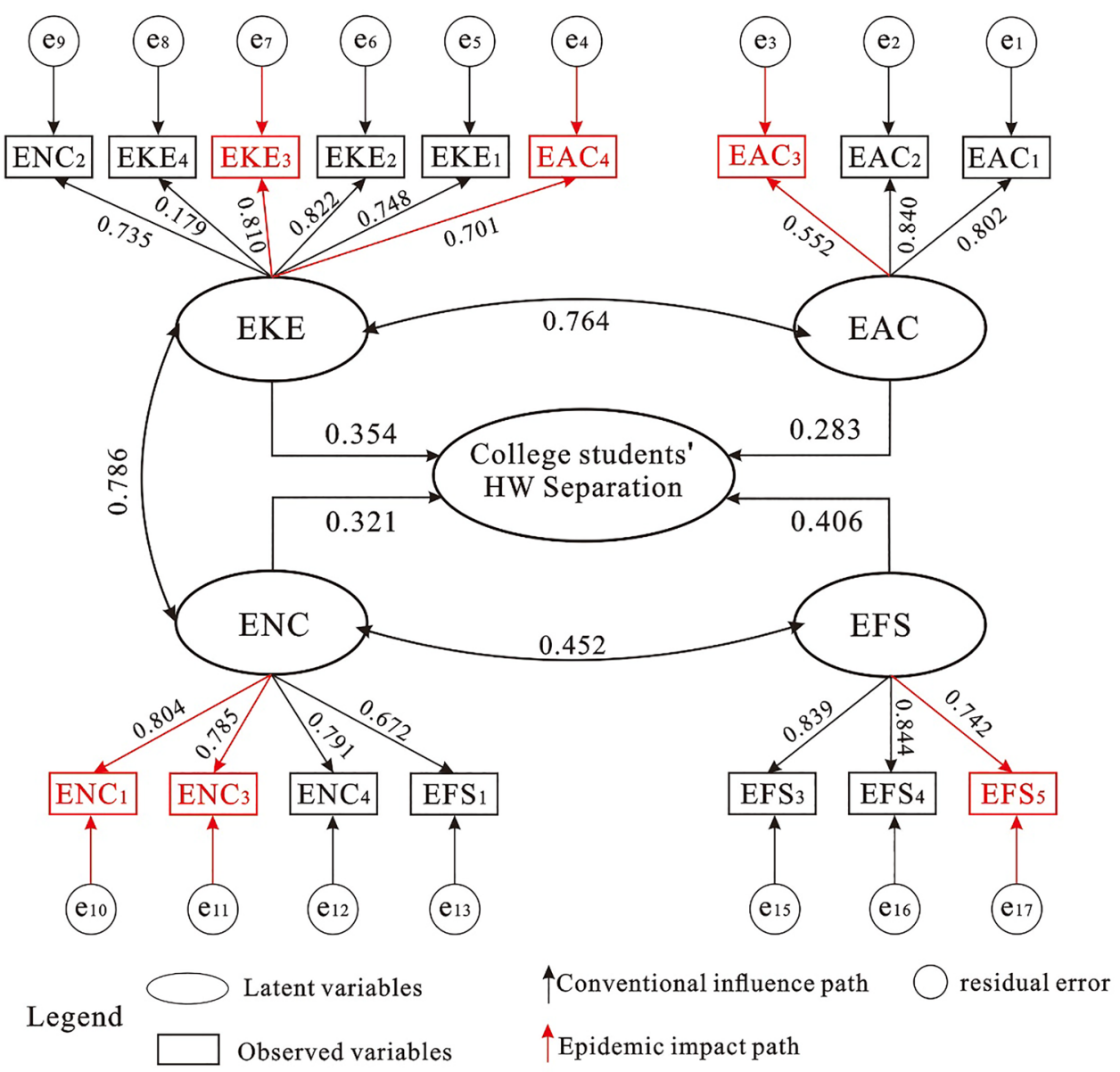

form. Therefore, path $\mathrm{H}_{8}$ of $\mathrm{EKE}_{4}$ is deleted and the model has been modified again.

\section{Analysis of modified SEM}

As can be seen from the initial SEM test parameters in Supplementary Table 3, the goodness-of-fit values of the initial model is not good and needs to be further expanded and modified. AMOS program provides the goodness-of-fit of the whole model and Modification Indices (MI) of each possible parameter not specified in the original model. Modification Indices search for a high MI between the observed variables and the error terms, and it is shown pairwise. If the MI values between the two observed variables are greater than 4 , it indicates that adding the path (the two-way covariant relationship between the observed variables) to the initial SEM may improve the fitting effect of the model and then obtain the modified SEM [56, 57].

According to the MI value test, there are four groups of error variables with MI values greater than 4 . The MI value of the residual errors $\mathrm{e}_{1}$ and $\mathrm{e}_{2}, \mathrm{e}_{3}$ and $\mathrm{e}_{4}$ in the latent variable EAC is relatively larger, reaching 27.504 and 18.675 , respectively. Thus, there is a strong correlation between $\mathrm{EAC}_{1}$ and $\mathrm{EAC}_{2}$, and a strong correlation between $\mathrm{EAC}_{3}$ and $\mathrm{EAC}_{4}$. The MI value of residual errors $\mathrm{e}_{6}$ and $\mathrm{e}_{7}$ in latent variable EKE is relatively larger reaching 28.631, which indicates that there is a strong correlation between $\mathrm{EKE}_{2}$ and $\mathrm{EKE}_{3}$. The MI value of the residual errors $\mathrm{e}_{10}$ and $\mathrm{e}_{11}$ in the latent variable ENC is relatively larger reaching 23.785, which means that there is a strong correlation between $\mathrm{ENC}_{1}$ and $\mathrm{ENC}_{3}$. Therefore, the residual correlation paths between $\mathrm{e}_{1}$ and $\mathrm{e}_{2}, \mathrm{e}_{3}$ and $\mathrm{e}_{4}, \mathrm{e}_{6}$ and $\mathrm{e}_{7}$, $\mathrm{e}_{10}$ and $\mathrm{e}_{11}$ are considered to improve the significance level of the parameters in the modified SEM.

Finally, the Chi-square value of the modified model is $216.453(P<0.00)$, the degree of freedom is 86 , and the $\mathrm{Cmin} / \mathrm{df}$ is 2.517 , which indicates that the modified model has a significant degree of adaptation. Compared with the results of fitting index calculation after the modified SEM (Supplementary Table 3), it can be found that the Chisquare value decreased from 613.832 to 216.453 . Each fitting index is better than the initial SEM before modified, and the goodness-of-fit index GFI, comparative fitting index CFI, normalized fitting index NFI and incremental fitting index IFI are all greater than 0.90 , indicating that 
Table 3 Significant path coefficient of the initial model

\begin{tabular}{|c|c|c|c|c|}
\hline Hypothesized relationship paths & & $\begin{array}{l}\text { Standardized regression } \\
\text { weight estimates }\end{array}$ & $\begin{array}{l}\text { Statistic test } \\
\text { parameter }\end{array}$ & $P$ value (strength of support) \\
\hline H1 & $\mathrm{EAC} \rightarrow \mathrm{EAC}_{1}$ & 0.802 & 8.684 & *** (Strong Support) \\
\hline $\mathrm{H} 2$ & $\mathrm{EAC} \rightarrow \mathrm{EAC}_{2}$ & 0.840 & 11.315 & $* * *$ (Strong support) \\
\hline $\mathrm{H} 3$ & $\mathrm{EAC} \rightarrow \mathrm{EAC}_{3}$ & 0.552 & 5.504 & $* * *$ (Strong support) \\
\hline $\mathrm{H} 4$ & $\mathrm{EKE} \rightarrow \mathrm{EAC}_{4}$ & 0.701 & 6.917 & $* * *$ (Strong support) \\
\hline H5 & $\mathrm{EKE} \rightarrow \mathrm{EKE}_{1}$ & 0.748 & 7.219 & $* * *$ (Strong support) \\
\hline H6 & $\mathrm{EKE} \rightarrow \mathrm{EKE}_{2}$ & 0.822 & 9.455 & $* * *$ (Strong support) \\
\hline $\mathrm{H} 7$ & $\mathrm{EKE} \rightarrow \mathrm{EKE}_{3}$ & 0.810 & 9.019 & $* * *$ (Strong support) \\
\hline $\mathrm{H} 8$ & $\mathrm{EKE} \rightarrow \mathrm{EKE}_{4}$ & 0.179 & 1.641 & 0.066 (not support) \\
\hline H9 & $\mathrm{ENC} \rightarrow \mathrm{ENC}_{1}$ & 0.804 & 8.833 & $* * *$ (Strong support) \\
\hline $\mathrm{H} 10$ & $\mathrm{EKE} \rightarrow \mathrm{ENC}_{2}$ & 0.735 & 6.611 & $* * *$ (Strong support) \\
\hline H11 & $\mathrm{ENC} \rightarrow \mathrm{ENC}_{3}$ & 0.785 & 8.542 & $* * *$ (Strong support) \\
\hline H12 & $\mathrm{ENC} \rightarrow \mathrm{ENC}_{4}$ & 0.791 & 8.337 & $* * *$ (Strong support) \\
\hline H13 & $\mathrm{ENC} \rightarrow \mathrm{EFS}_{1}$ & 0.672 & 6.558 & $* * *$ (Strong support) \\
\hline H15 & $\mathrm{EFS} \rightarrow \mathrm{EFS}_{3}$ & 0.839 & 11.268 & $* * *$ (Strong support) \\
\hline H16 & $\mathrm{EFS} \rightarrow \mathrm{EFS}_{4}$ & 0.844 & 12.135 & $* * *$ (Strong support) \\
\hline H17 & $\mathrm{EFS} \rightarrow \mathrm{EFS}_{5}$ & 0.742 & 8.231 & $* * *$ (Strong support) \\
\hline EAC $\rightarrow$ College students' HW separation & & 0.283 & 4.838 & 0.020 (Support) \\
\hline $\mathrm{EKE} \rightarrow$ College students' HW separation & & 0.354 & 6.027 & $* * *$ (Strong support) \\
\hline $\mathrm{ENC} \rightarrow$ College students' HW separation & & 0.321 & 5.136 & $* * *$ (Strong support) \\
\hline EFS $\rightarrow$ College students' HW separation & & 0.406 & 7.528 & $* * *$ (Strong support) \\
\hline
\end{tabular}

“***” represents significant at the 0.01 level. This study takes the $95 \%$ confidence interval, that is, if the $P$ value is significant at the 0.05 level, then the path coefficient is considered to be significant

the constructed model of college students' HW separation behavior has a better fitting degree.

The estimated value of the standardized path coefficient added in the modified model is shown in Fig. 5. The results show that the value of the 15 standardized path coefficients on the outside represents the direct influence of the observed variables on the latent variables, the value of the four standardized path coefficients in the middle represents the direct influence of the latent variables on the target variables (waste separation behavior of college students in the post COVID-19 pandemic period), and the product of the two represents the indirect influence of the observed variables on the target variables. For example,

the influence degree of "awareness of resource conservation and environmental protection $\left(\mathrm{EAC}_{1}\right)$ " on "HW separation behavior of college students" is: $0.805 \times 0.296 \approx 0.238$.

The influence degree of "willingness to participate $\left(\mathrm{EAC}_{2}\right)$ " on "HW separation behavior of college students" is $0.816 \times 0.296=0.241$.

The influence degree of "environmental health awareness $\left(\mathrm{EAC}_{3}\right)$ " on "HW separation behavior of college students" is: $0.609 \times 0.296=0.180$.

It means that the influence degree of "basic environmental literacy", "environmental behavior attitude" and "environmental sanitation awareness" on college students' HW separation behavior is $0.238,0.241$ and 0.180 , respectively. Every time these three factors increase by one unit, the effect of college students' HW separation behavior will increase by $0.238,0.241$ and 0.180 , respectively, in the post COVID-19 pandemic period.

Similarly, through the above structural equation model fitting analysis, the main influencing factors of college students' HW separation behavior and the corresponding sensitivity coefficient of each factor are obtained. The sensitivity coefficient indicates the comprehensive influence degree of each factor on the waste separation behavior of college students in the post COVID-19 pandemic period. The fitting results and the importance ranking of each factor are shown in Table 4. For the four latent variables, EFS had the largest comprehensive impact on HW separation (0.422), followed by EKE (0.395) and ENC (0.341) and finally EAC (0.296).

In Table 4, the 15 different impact factors are further divided into two path types, subjective intrinsic factors and external situational factors. The subjective intrinsic factors mainly reflect the impact of individual ideology, knowledge cognition and behavior attitude on HW separation. The external situational factors mainly reflect the influence of policies and rules, surrounding classmates, incentive of economic benefits and garbage sorting facilities. On the whole, the HW separation behavior of college students in the post COVID-19 
Fig. 5 Results of parameter estimation of the modified SEM

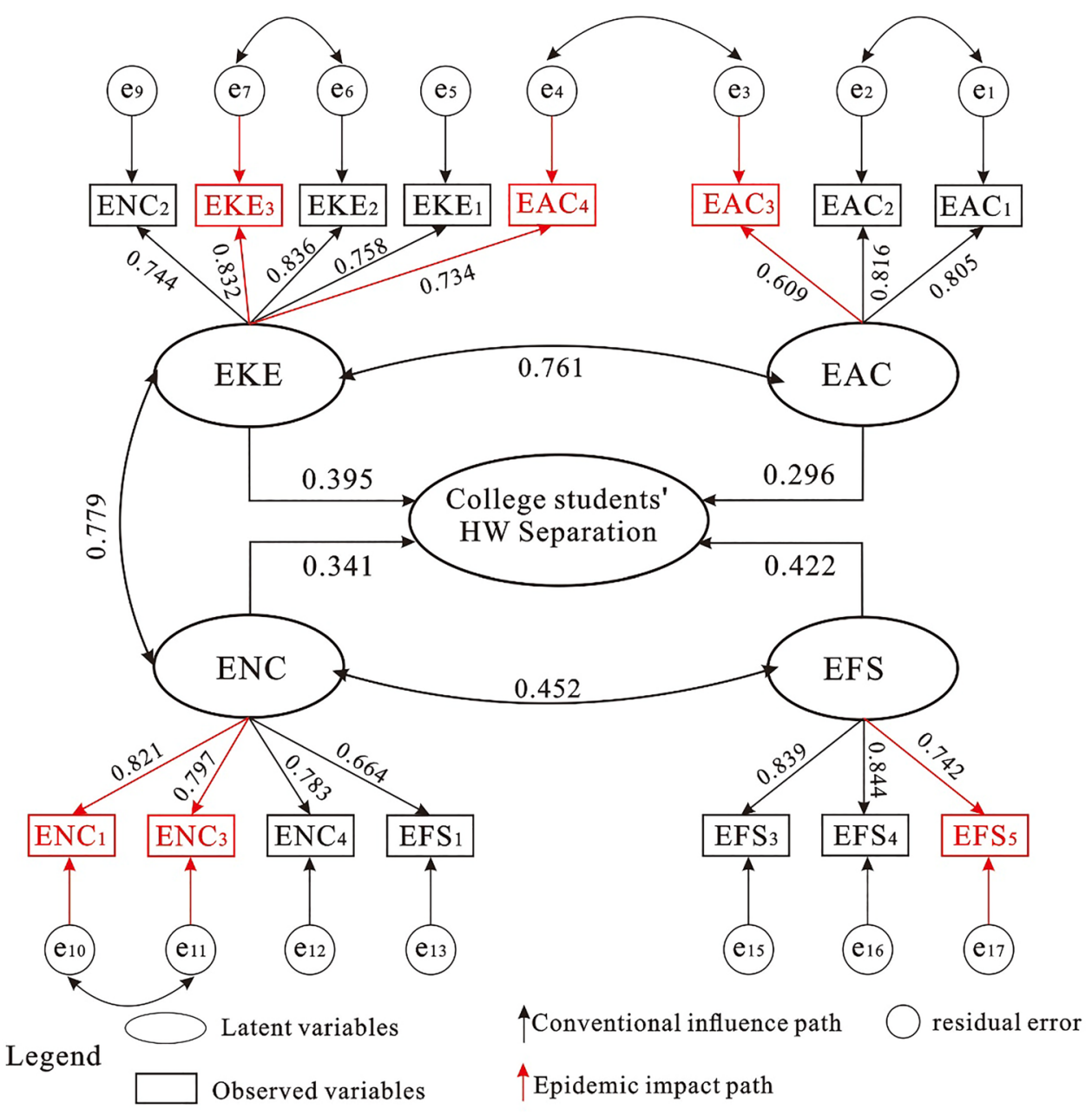

pandemic period is mainly affected by eight subjective intrinsic factors and seven external situational factors, and the influence degree of the two factors is generally close. The comprehensive influence value of external situational factors on college students' HW separation behavior is 2.138 , which is slightly higher than the comprehensive influence degree of subjective internal factors of 2.130. The average influence degree of external situational factors is 0.305 , which is also slightly higher than the subjective intrinsic factors of 0.266 . Also, the comprehensive influence value of six epidemicrelated factors is 1.663 , the comprehensive influence value of nine conventional influence paths is 2.605 and the average value of epidemic impact paths is 0.277 , which was slightly lower than that of conventional influence paths (0.289). Therefore, it can be found that the COVID-19 pandemic factor is also an important influencing aspect of college students' HW separation behavior.

\section{Discussion and policy implication}

Based on the above findings, we propose the following policy recommendations:

1. The administrative departments of colleges should pay attention to the positive influence of the epidemic path on college students' waste separation behavior. The previous analysis has shown that the epidemic impact path is an important dimension affecting college students' waste separation behavior; both society and colleges should persist in epidemic control and waste separation [58]. Not only college students but also the whole society has been aware of the importance of forming satisfying living and health habits through the epidemic, which can urge the residents to actively participate in 
Table 4 Fitting results of the structural equation model for students' HW separation

\begin{tabular}{|c|c|c|c|c|}
\hline Latent variables & Observed variables (factors) & $\begin{array}{l}\text { Sensitivity coefficients } \\
\text { (standardized estimate) }\end{array}$ & $\begin{array}{l}\text { Impor- } \\
\text { tance } \\
\text { ranking }\end{array}$ & Path type \\
\hline \multirow[t]{3}{*}{$\begin{array}{l}\text { Environmental Attitude and Conscious- } \\
\text { ness (EAC) }\end{array}$} & $\begin{array}{l}\text { Awareness of resource conservation and } \\
\text { environmental protection }\left(\mathrm{EAC}_{1}\right)\end{array}$ & 0.238 & 13 & Subjective intrinsic \\
\hline & Willingness to participate $\left(\mathrm{EAC}_{2}\right)$ & 0.241 & 12 & Subjective intrinsic \\
\hline & $\begin{array}{l}\text { Environmental hygiene awareness } \\
\left(\mathrm{EAC}_{3}\right)\end{array}$ & 0.180 & 15 & Subjective intrinsic \\
\hline \multirow[t]{5}{*}{$\begin{array}{l}\text { Environmental Knowledge and Educa- } \\
\text { tion (EKE) }\end{array}$} & $\begin{array}{l}\text { Change of environmental behavior } \\
\text { attitude in epidemic situation }\left(\mathrm{EAC}_{4}\right)\end{array}$ & 0.290 & 8 & Subjective intrinsic \\
\hline & $\begin{array}{l}\text { Basic knowledge of classified recycling } \\
\left(\mathrm{EKE}_{1}\right)\end{array}$ & 0.299 & 6 & Subjective intrinsic \\
\hline & $\begin{array}{l}\text { Classified publicity and education } \\
\left(\mathrm{EKE}_{2}\right)\end{array}$ & 0.330 & 3 & Subjective intrinsic \\
\hline & $\begin{array}{l}\text { Publicity and education intensity after } \\
\text { the epidemic }\left(\mathrm{EKE}_{3}\right)\end{array}$ & 0.328 & 4 & External situational \\
\hline & $\begin{array}{l}\text { The influence of surrounding classmates } \\
\left(\mathrm{ENC}_{2}\right)\end{array}$ & 0.294 & 7 & External situational \\
\hline \multirow[t]{4}{*}{$\begin{array}{l}\text { Environmental Norms and Constraints } \\
\text { (ENC) }\end{array}$} & $\begin{array}{l}\text { Social responsibility of college students } \\
\left(\mathrm{ENC}_{1}\right)\end{array}$ & 0.280 & 9 & Subjective intrinsic \\
\hline & The leading role of activists $\left(\mathrm{ENC}_{3}\right)$ & 0.272 & 10 & Subjective intrinsic \\
\hline & $\begin{array}{l}\text { The binding role of school discipline and } \\
\text { rules }\left(\mathrm{ENC}_{4}\right)\end{array}$ & 0.267 & 11 & External situational \\
\hline & $\begin{array}{l}\text { The incentive of economic benefits of } \\
\text { waste collection }\left(\mathrm{EFS}_{1}\right)\end{array}$ & 0.226 & 14 & External situational \\
\hline \multirow[t]{3}{*}{$\begin{array}{l}\text { Environmental Facilities and Services } \\
\text { (EFS) }\end{array}$} & $\begin{array}{l}\text { The convenience of sorting facilities } \\
\left(\mathrm{EFS}_{3}\right)\end{array}$ & 0.354 & 2 & External situational \\
\hline & $\begin{array}{l}\text { The convenience of recycling facilities } \\
\left(\mathrm{EFS}_{4}\right)\end{array}$ & 0.356 & 1 & External situational \\
\hline & $\begin{array}{l}\text { The good operation of recycling facili- } \\
\text { ties }\left(\mathrm{EFS}_{5}\right)\end{array}$ & 0.313 & 5 & External situational \\
\hline
\end{tabular}

Subjective intrinsic factors mainly reflect the impact of individual ideology, knowledge cognition and behavior attitude on HW separation. External situational factors mainly reflect the influence of policies and rules, surrounding classmates, incentive of economic benefits, and garbage sorting facilities. Besides, the observed variables in bold are the epidemic impact path

the source classification of waste. In the long run, it is the public's responsibility to enhance their ecological quality and fulfill eco-friendly living habits by waste separation. Therefore, the pandemic is a crisis as well as an opportunity for every citizen to enhance HW separation and contribute to the prevention and control of the epidemic, laying a solid foundation for the full implementation of waste separation across the country.

2. The results of the previous study indicate that environmental facilities and services influence most college students' HW separation behavior, and the convenience and good functions of the separation and recycling facilities are the key factors affecting college students' waste separation on behavior. The results are in line with the conclusion drawn by Meng et al. [24]. As a result, colleges should constantly improve the construction of supporting facilities for HW separation and well design relevant signs on campus. Here, supporting facilities refer to dif- ferent kinds of trash cans, special trash cans for masks and gloves, intelligent waste sorting and recycling facilities, different kinds of garbage bags and garbage sorting signs. On the one hand, colleges should accelerate the complete back-end operation system handling collection, transportation and disposal of HW and promote an intelligent recycling system to encourage college students' involvement in the front-end classification and dumping. On the other hand, colleges should facilitate the convenience and accuracy of waste separation by equipping with sufficient facilities, defining specific signs, ensuring the smooth operation of back-end disposal and recycling facilities. For college students, they have a relatively standardized daily life management regulation, complete waste classification and recycling supporting facilities, which is conducive to the implementation of their waste separation behavior [11]. 
3. Previous studies showed that that environmental education and publicity are important factors that influence college students' waste separation behavior. Therefore, it is necessary to strengthen the publicity of campus waste classification knowledge to enhance students' willingness to actively participate in waste separation. Besides, the civilized behavior of college students is also a contribution to society in terms of waste separation awareness improvement. It is recognized that the popularity of waste classification knowledge and reinforcement of environment and ecology civilization education are significant measures to cultivate college students' social responsibility in the awareness of HW separation. For one thing, colleges can organize competitions for waste classification knowledge, rewarding exemplary individuals and Youth League branches, to popularize waste classification knowledge and inspire students to take part in the waste separation activities. For another, college students should be encouraged to focus on energy and environmental issues, to develop their sense of value and responsibility. Take one college in Ningbo as an example; the college has posted Make Waste Classification a Fashion on campus. However, it cannot be denied that, with various problems of individual consciousness, living habits and recycling facilities on campus, waste separation on campus will be a lasting battle involving joint efforts between colleges and their students.

4. Compared with the research hypothesis and results conducted by Meng et al.[24], this study found out that environment norms and constraints play an indispensable part in the analysis frame, especially in those cities, e.g. Ningbo, where HW classification institutions have been put into effect. Due to the lack of strict restraints, residents are unwilling to participate in HW separation. And it is also the case in colleges. Consequently, governments at all levels should establish and improve the legal and regulatory system, incentive mechanism and restrictive policies for waste separation and disposal and standardize the source classification system of HW separation. Meanwhile, colleges should keep the students informed of all the national and local policies and implement them on campus. In addition, colleges should formulate their own regulations on campus to encourage students to participate in the activities and restrain violation of the regulations. With the extensive cooperation among the governments, colleges and social media, from diverse channels, students' comprehension of these policies can be enhanced through intensive publicity of the policies. With the establishment of joint efforts and mutual supervision mechanism, students' enthusiasm in HW separation will be stimulated.

\section{Conclusions}

With the adoption of online + offline social survey and structural equation model, based on the data collected from 10 colleges' students in Ningbo, this study explores college students' HW separation behavior decision-making mechanism in the post COVID-19 pandemic period. The results indicated the following:

1. On the whole, college students' waste separation behavior is mainly decided by eight subjective intrinsic factors and seven external situational factors, and the comprehensive influence level of the two dimensions is relatively close. The comprehensive impact value of external situational factors reaches 2.138 , which is slightly higher than that of the subjective intrinsic factors, reaching 2.130. Similarly, the average impact degree value of external situational factors is 0.305 , higher than that of subjective intrinsic factors, reaching 0.266 .

2. In terms of path type, the comprehensive impact value of the six epidemic-related factors is 1.663 , while the counterpart of the nine conventional paths is 2.605 . The mean value of epidemic factors reaching 0.277 is slightly lower than that of conventional factors reaching 0.289 . Therefore, the epidemic factors significantly affect the college students' HW separation behavior. In the future, society and colleges should persist in the prevention and control of the pandemic and HW separation.

3. Of all the four latent variables, EFS had the largest comprehensive impact on HW separation (0.422), followed by EKE (0.395) and ENC (0.341) and finally EAC (0.296). As for the single factor, the threemost influential factors are the convenience of recycling facilities $\left(\mathrm{EFS}_{3}\right)$, the convenience of classification facilities $\left(\mathrm{EFS}_{4}\right)$ and publicity and education of classification knowledge $\left(\mathrm{EKE}_{2}\right)$. However, economic returns play a relatively minor role in college students' intention of participation in HW separation.

4. ENC is indispensable in the analysis frame of college waste separation behaviors. In the long run, colleges should popularize all the national and local policies and implement them on campus. In addition, colleges should formulate their own regulations on campus to encourage students to participate in the activities and restrain a violation of these regulations.

With its normalization in people's daily life, the epidemic will have a more profound effect on residents' behaviors. It is advised for further studies to enrich the theory of environmental behavior by expanding the sample cities and analyzing the residents' behaviors influenced by 
different severity of the epidemic and their implementation of waste separation.

Supplementary Information The online version contains supplementary material available at https://doi.org/10.1007/s10163-022-01363-3.

Acknowledgements This work was supported by the First Teaching Reform and Research Projects of the 13th Five-year Plan of Zhejiang Higher Education (jg20180576).

\section{References}

1. Alhassan H, Kwakwa PA, Owusu-Sekyere E (2020) Households' source separation behaviour and solid waste disposal options in Ghana's Millennium City. J Environ Manage 259:110055

2. Wang H, Liu X, Wang N, Zhang K et al (2020) Key factors influencing public awareness of household solid waste recycling in urban areas of China: a case study. Resour Conserv Recycl 158:104813

3. Requena-Sanchez N, Carbonel-Ramos D, Campodónico LFD (2021) A novel methodology for household waste characterization during the COVID-19 pandemic: case study results. J Mater Cycles Waste Manag. https://doi.org/10.1007/ s10163-021-01309-1

4. Ye Q, Anwar MA, Zhou R et al (2020) China's green future and household solid waste: challenges and prospects. Waste Manage 105:328-338

5. Zhang LP, Zhu ZP (2020) Can smart waste bins solve the dilemma of household solid waste sorting in China? A case study of Fuzhou City. Pol J Environ Manage 29(5):3943-3954

6. Tucker P, Murney G, Lamont J (1998) Predicting recycling scheme performance: a process simulation approach. J Environ Manage 53(1):31-48

7. Sharma HB, Vanapalli KR, Cheela VS et al (2020) Challenges, opportunities, and innovations for effective solid waste management during and post COVID-19 pandemic. Resour Conserv Recycl 162:105052

8. Kulkarni BN, Anantharama V (2020) Repercussions of COVID19 pandemic on municipal solid waste management: challenges and opportunities. Sci Total Environ 743:140693

9. Adelodun B, Ajibade FO, Ibrahim RG et al (2021) Insights into hazardous solid waste generation during COVID-19 pandemic and sustainable management approaches for developing countries. J Mater Cycles Waste Manag 23:2077-2086

10. Van Fan Y, Jiang P, Hemzal M (2020) An update of COVID-19 influence on waste management. Sci Total Environ 754:142014

11. Zhang H, Liu J, Wen ZG (2017) College students' municipal solid waste source separation behavior and its influential factors: a case study in Beijing, China. J Clean Prod 164:444-454

12. Wang R, Qi R, Cheng J et al (2020) The behavior and cognition of ecological civilization among Chinese university students. J Clean Prod 243:118464

13. Si H, Shen L, Liu W, Wu G (2021) Uncovering people's masksaving intentions and behaviors in the post-COVID-19 period: Evidence from China. Sustain Cities Soc 65:102626

14. Vanapalli KR, Sharma HB, Ranjan VP et al (2021) Challenges and strategies for effective plastic waste management during and post COVID-19 pandemic. Sci Total Environ 750:141514

15. Xie H-B (2020) Investigation and analysis on the implementation of household waste classification in Ningbo. Ningbo Econ (Sanjiang Forum) 11:34-36 ((in Chinese, 2020))

16. Tran VCM, Matsui Y (2021) Predicting the effect of promotion measures on waste separation behavior: a case study in Da Nang
City, Vietnam. J Mater Cycles Waste Manag. https://doi.org/10. 1007/s10163-021-01300-w

17. Ajzen I, Fishbein M (1977) Attitude-behavior relations: a theoretical analysis and review of empirical research. Psychol Bull 84(5): 888

18. Ajzen I (1985) From intentions to actions: a theory of planned behavior. Action-Control Cogn Behav 1-63

19. Chan K (1998) Mass communication and pro-environmental behaviour: waste recycling in Hong Kong. J Environ Manage 52(4):317-325

20. Nguyen TP, Zhu D, Le NP (2015) Factors influencing waste separation intention of residential households in a developing country: evidence from Hanoi. Vietnam Habitat Int 48:169-176

21. Park J, Ha S (2014) Understanding consumer recycling behavior: combining the theory of planned behavior and the norm activation model. Fam Consum Sci Res J 42(3):278-291

22. Cheng KW, Osman S, Jusoh ZM et al (2021) Multidimensional factors that influence the intention to practice segregation-atsource of solid waste: an empirical study. Manage Sci Lett 11(2):379-390

23. Boldero J (1995) The prediction of household recycling of newspapers: the role of attitudes, intentions, and situational factors. J Appl Soc Psychol 25(5):440-462

24. Meng X, Tan X, Wang Y et al (2019) Investigation on decision-making mechanism of residents' household solid waste classification and recycling behaviors. Resour Conserv Recycl 140:224-234

25. Stern PC, Oskamp S (1987) Managing scarce environmental resources. Handbook of environmental psychology. Wiley, New York

26. Guagnano GA, Stern PC, Dietz T (1995) Influences on attitudebehaviour relationships: a natural experiment with curbside recycling. Environ Behav 27(5):699-718

27. Ouhsine O, Ouigmane A, Layati E et al (2020) Impact of COVID-19 on the qualitative and quantitative aspect of household solid waste. Glob J Environ Sci Manage 6(4):1-12

28. Sadeghi S, Asadi ZS, Rakhshani T (2020) The effect of an educational intervention based on the Integrated Behavior Model (IBM) on the waste separation: a community based study. Clin Epidemiol Glob Health 8(2):576-580

29. Bortoleto AP, Kurisu KH, Hanaki K (2012) Model development for household waste prevention behaviour. Waste Manag 32:2195-2207

30. Fan B, Yang W, Shen X (2019) A comparison study of "motivation-intention-behavior" model on household solid waste sorting in China and Singapore. J Clean Prod 211:442-454

31. Wu Z, Zhang Y, Chen Q, Wang H (2020) Attitude of Chinese public towards municipal solid waste sorting policy: a text mining study. Sci Total Environ 142674

32. Grazhdani D (2016) Assessing the variables affecting on the rate of solid waste generation and recycling: an empirical analysis in Prespa Park. Waste Manage 48:3-13

33. Wang Z, Guo D, Wang X et al (2018) How does information publicity influence residents' behaviour intentions around e-waste recycling? Resour Conserv Recycl 133:1-9

34. Wan C, Shen GQ, Yu A (2015) Key determinants of willingness to support policy measures on recycling: a case study in Hong Kong. Environ Sci Policy 54:409-418

35. Izagirre-Olaizola J, Fernández-Sainz A, Vicente-Molina MA (2015) Internal determinants of recycling behaviour by university students: a cross-country comparative analysis. Int J Consum Stud 39(1):25-34

36. Lindbeck A (1997) Incentives and social norms in household behavior. Am Econ Rev 87(2):370-377 
37. Ward BW (2011) Identifying environmental effects on alcohol use and social-norms: the socio-environmental context model. J Hum Behav Soc Environ 21(5):502-520

38. Botetzagias I, Dima AF, Malesios C (2015) Extending the theory of planned behavior in the context of recycling: the role of moral norms and demographic predictors. Resour Conserv Recycl 95:58-67

39. Wan C, Shen GQ, Yu A (2014) The role of perceived effectiveness of policy measures in predicting recycling behavior in Hong Kong. Resour Conserv Recycl 83(83):141-151

40. Li X, Bi F, Han Z (2019) Garbage source classification performance, impact factor, and management strategy in rural areas of China: a case study in Hangzhou. Waste Manage 89:313-321

41. Matsumoto S (2014) The opportunity cost of pro-environmental activities: spending time to promote the environment. J Fam Econ Issues 35(1):119-130

42. Chen T, Zhao Y, Qiu X et al (2021) Economics analysis of food waste treatment in China and its influencing factors. Front Environ Sci Eng 15(2):1-12

43. Bach H, Mild A, Natter M et al (2004) Combining socio-demographic and logistic factors to explain the generation and collection of waste paper. Resour Conserv Recycl 41(1):65-73

44. Abbott A, Nandeibam S, O'Shea L (2011) Explaining the variation in household recycling rates across the UK. Ecol Econ 70(11):2214-2223

45. Villalba L, Donalisio RS, Basualdo NEC (2020) Household solid waste characterization in Tandil (Argentina): socioeconomic, institutional, temporal and cultural aspects influencing waste quantity and composition. Resour Conserv Recycl 152:104530

46. Reddi KR, Li W, Wang B et al (2013) System dynamics modelling of hybrid renewable energy systems and combined heating and power generator. Int J Sustain Eng 6(1):31-47

47. Wu SJ, Bai X, Fiske ST (2018) Admired rich or resented rich? How two cultures vary in envy. J Cross Cult Psychol 49(7):1114-1143

48. Jöreskog KG (1970) A general method for estimating a linear structural equation system. Res Bull 2:1-41
49. Dell' Olio L, Ibeas A, Oña J et al (2018) Structural equation models. Chapter 8. Public transportation quality of service. Elsevier, Oxford, pp 141-154

50. Tong D, Yuan Y, Wang X (2021) The coupled relationships between land development and land ownership at China's urban fringe: a structural equation modeling approach. Land Use Policy 100:104925

51. Lee P, Mahoney KT, Lee S (2017) An application of the exploratory structural equation modeling framework to the study of personality faking. Pers Indiv Diff 119:220-226

52. Kim YK, Lee HR (2011) Customer satisfaction using low cost carriers. Tour Manag 32(2):235-243

53. Tenenhaus M, Vinzi VE, Chatelin YM et al (2005) PLS path modeling. Comput Stat Data Anal 48(1):159-205

54. Liu J, Yi Y, Wang X (2020) Exploring factors influencing construction waste reduction: a structural equation modeling approach. J Clean Prod 276:123185

55. Singh S, Dhir S, Das VM, Sharma A (2020) Bibliometric overview of the technological forecasting and social change journal: analysis from 1970 to 2018. Technol Forecast Soc 154:119963

56. Ihm J (2018) Social implications of children's smartphone addiction: the role of support networks and social engagement. J Behav Addict 7(2):473-481

57. Dash G, Paul J (2021) CB-SEM vs PLS-SEM methods for research in social sciences and technology forecasting. Technol Forecast Soc 173:121092

58. Penteado CSG, de Castro MAS (2020) Covid-19 effects on municipal solid waste management: what can effectively be done in the Brazilian scenario? Resour Conserv Recycl 164:105152

Publisher's Note Springer Nature remains neutral with regard to jurisdictional claims in published maps and institutional affiliations. 